\title{
Efficient and stable reconstitution of the $A B C$ transporter BmrA for solid-state NMR studies
}

\author{
Britta Kunert ${ }^{1 \dagger}$, Carole Gardiennet ${ }^{1+}$, Denis Lacabanne ${ }^{1}$, Daniel Calles-Garcia ${ }^{1}$, Pierre Falson ${ }^{1}$, \\ Jean-Michel Jault ${ }^{1}$, Beat H. Meier ${ }^{2}$, François Penin ${ }^{1}$ and Anja Böckmann ${ }^{1}{ }^{*}$ \\ Labex Ecofect, Bases Moleculaires et Structurales des Systemes Infectieux, UMR 5086 CNRS, IBCP, Université de Lyon 1, Lyon, France \\ 2 Physical Chemistry, ETH Zürich, Zurich, Switzerland
}

\section{Edited by:}

Piero Andrea Temussi, Università di

Napoli Federico II, Italy

Reviewed by:

Francesca M. Marassi,

Sanford-Burnham Medical Research

Institute, USA

Clemens Glaubitz, Goethe

University Frankfurt, Germany

\section{*Correspondence:}

Anja Böckmann, Bases Moléculaires

et Structurales des Systèmes

Infectieux, UMR 5086 CNRS, IBCP

Université de Lyon 1, 7 Passage du

Vercors, F-69367, France

e-mail: a.bockmann@ibcp.fr

tThese authors have contributed equally to this work.
We present solid-state NMR sample preparation and first 2D spectra of the Bacillus subtilis ATP-binding cassette $(\mathrm{ABC})$ transporter BmrA, a membrane protein involved in multidrug resistance. The homodimeric $130-\mathrm{kDa}$ protein is a challenge for structural characterization due to its membrane-bound nature, size, inherent flexibility and insolubility. We show that reconstitution of this protein in lipids from Bacillus subtilis at a lipid-protein ratio of $0.5 \mathrm{w} / \mathrm{w}$ allows for optimal protein insertion in lipid membranes with respect to two central NMR requirements, high signal-to-noise in the spectra and sample stability over a time period of months. The obtained spectra point to a well-folded protein and a highly homogenous preparation, as witnessed by the narrow resonance lines and the signal dispersion typical for the expected secondary structure distribution of BmrA. This opens the way for studies of the different conformational states of the transporter in the export cycle, as well as on interactions with substrates, via chemical-shift fingerprints and sequential resonance assignments.

Keywords: solid-state NMR, ABC-transporter, BmrA, isotope labeling, B. subtilis lipids

\section{INTRODUCTION}

Studies of membrane proteins in a membrane environment are key to understand their function at the molecular level, and solid-state NMR presents a promising method to address central structural questions. This emerging technique for the investigation of conformational details of insoluble and non-crystalline molecular assemblies has gone through major advances in the last years, and is on the way to become an important tool in structural biology (Böckmann, 2008; Lesage et al., 2008; Lorieau et al., 2008; Loquet et al., 2009; Böckmann and Meier, 2010; Jehle et al., 2010; Schuetz et al., 2010; Su et al., 2010; Van Melckebeke et al., 2010; Linser et al., 2011; Cukkemane et al., 2012). In principle, solid-state NMR is able to investigate large molecular assemblies, and does not require the presence of crystalline long-range order in three or two dimensions, nor soluble samples. It can investigate various kinds of biological material, as protein fibrils (Heise et al., 2005; Ferguson et al., 2006; Wasmer et al., 2008, 2009; Loquet et al., 2009; Barbet-Massin et al., 2010; Böckmann and Meier, 2010; Debelouchina et al., 2010; Helmus et al., 2010; Van Melckebeke et al., 2010; Comellas et al., 2011; Tycko, 2011; Sinnige et al., 2014), membrane proteins in different environments, including phospholipid bilayers (Andronesi et al., 2005; Lorch et al., 2005; Lange et al., 2006; McDermott, 2009; Shi et al., 2011; Emami et al., 2013), and 2D or 3D crystalline assemblies, regardless of the crystal size and diffraction properties. The initial studies using solid-state NMR techniques to characterize membrane proteins are very promising (Hiller et al., 2005; van Gammeren et al., 2005; Lange et al., 2006, 2010; Etzkorn et al., 2008; Li et al., 2008; Higman et al., 2009; Shi et al., 2009; Bhate et al., 2010; Cady et al., 2010).

The NMR methods mentioned above are based on the collection of distance and torsion-angle restraints which are then the basis of a structure calculation in analogy to the classical structure determination in solution-state NMR (Wüthrich, 2003). It is worth mentioning that for membrane proteins, solid-state NMR structure determination can alternatively be performed on the basis of orientational restraints obtained from measuring bond directions (e.g., for backbone amide N-H bonds) either in oriented samples (Ketchem et al., 1997; Opella et al., 1999; Marassi and Opella, 2000; Opella and Marassi, 2004; Claramunt et al., 2010; Sharma et al., 2010; Das et al., 2013; Cross et al., 2014; Murray et al., 2014a,b) or by rotationally oriented methods (Park et al., 2012; Das et al., 2014) which can also be combined with distance restraints.

Solid-state NMR is, by its capability of investigating proteins in their near-native environment and at physiological temperatures, complementary to other biophysical methods, as $\mathrm{X}$-ray crystallography, which is currently the most successful method for protein 3D structure determination in general, and of $\mathrm{ABC}$ transporters in particular, and which will further benefit by the availability of free electron lasers (Barends et al., 2014). Importantly, recent considerable progress toward quasiatomic resolution structures has also been made by cryo-electron microscopy (Liao et al., 2013; Kühlbrandt, 2014). NMR studies shall be able to contribute, in combination with other techniques, to obtain the most complete view on structures, as well as of dynamic behavior, of the important class of membrane proteins. 
As is true for the other structural approaches as well, membrane protein sample preparation for solid-state NMR remains a challenge, which is in the context of solid-state NMR most noticeably due to the difficulties of membrane reconstitution, a central and critical step in sample preparation. To obtain spectra displaying narrow resonance lines, it is essential that all proteins are reconstituted in the membrane in the same manner, displaying a conformationally homogenous ensemble. Achieving membrane insertion with minimal protein loss is vital to maximize the NMR signal. Equally important, achieving long-term stability of reconstituted membrane proteins is fundamental to acquire highly resolved NMR spectra and to potentially repeat and optimize spectra over a period of several months.

$\mathrm{ABC}$ transporters are ubiquitous integral membrane proteins that energize the translocation of substrates across biological membranes by ATP hydrolysis, and are conserved from bacteria to humans (Higgins, 1992). These proteins work either as importers or exporters and are composed of two transmembrane domains (TMDs), forming the translocation pathway, and two highly conserved nucleotide-binding domains (NBDs), generating the energy for substrate translocation (Holland and Blight, 1999). Importers are almost only found in prokaryotes and require an extra-cytoplasmic binding protein for substrate recognition. In contrast, exporters are present in all organisms and can accept substrates directly from the cytoplasm or the lipid bilayer (Hollenstein et al., 2007). While some exporters are dedicated to transport a specific substrate (e.g., lipid A for MsbA Zhou et al., 1998), others remove a broad range of molecules from the cell, including xenobiotics such as antiviral, antibiotic, antifungal and anticancer agents in humans or antibiotics, antifungal or antiparasitic drugs in microorganisms. These multidrug transporters have thus been described as molecular "hydrophobic vacuum cleaners" and are promising therapeutic targets as they are involved in multidrug resistance phenotype (Ward et al., 2007; Aller et al., 2009). To find ways to modulate their activity in order to increase drug efficiency, it is necessary to understand how the transporters recognize such a wide variety of substrates (Martinez et al., 2014) and translocate them across the membrane during the catalytic cycle (Jones et al., 2009; Newstead et al., 2009; Ernst et al., 2010). Experience has shown that ABC exporters are extremely dynamic molecules (Hellmich et al., 2012; Mehmood et al., 2012), and the large conformational variability (Dawson and Locher, 2006, 2007; Ward et al., 2007; Aller et al., 2009; Hohl et al., 2012) including open, closed and several intermediate states makes a detailed structural characterization central to understanding their function.

The study of model transporter proteins of bacterial origin, for which overproduction yields quantities large enough for structural studies (i.e., several milligrams) and for stable isotopes enrichment (e.g., ${ }^{15} \mathrm{~N},{ }^{13} \mathrm{C}$ ), constitutes an important tool to further understand the building principles of their eukaryotic counterparts. First solid-state studies have been performed already a decade ago (Mason et al., 2004; Agarwal et al., 2007; Lehner et al., 2008) and a first high-resolution MAS solid-state NMR study of a thermophilic ABC importer, ArtMP from Geobacillus stearothermophilus, prepared in 2D crystalline form, has been reported recently (Lange et al., 2010). The authors have shown that amino-acid selective labeled ArtMP could be reconstituted in native lipid extracts yielding a homogenous solid-state NMR sample that gave rise to high-quality NMR spectra. Investigations, both in oriented media and by MAS NMR, of the homo-dimeric multidrug antiporter EmrE have also appeared recently (Gayen et al., 2013; Ong et al., 2013; Becker-Baldus and Glaubitz, 2014).

We here use the bacterial ABC exporter BmrA from Bacillus subtilis as a model. BmrA has been identified in the B. subtilis genome by homology search, displaying about $54 \%$ of identity, plus strong similarity with each half of the human P-glycoprotein (Steinfels et al., 2002), and 57\% of identity plus strong similarity with the Sav1866 homodimer (Dawson and Locher, 2006). BmrA functions as a homodimer of $\sim 130 \mathrm{kDa}$ (Dalmas et al., 2005), and its amino-acid sequence is shown in Figure S1, together with secondary structure elements and functional sequences, predicted by homology from E. coli MsbA in its apo-form (Ward et al., 2007; Do Cao et al., 2009). BmrA, as other exporters, is constituted of four domains: 2 transmembrane domains with 6 predicted $\alpha$-helices each, and two nucleotide binding domains (Dawson and Locher, 2006; Ward et al., 2007; Aller et al., 2009). We report here the first steps toward conformational studies of BmrA by solid-state NMR, including protein production and efficient reconstitution in lipids, as well as sample-quality assessment.

\section{MATERIALS AND METHODS}

The detergents $\mathrm{n}$-Dodecyl- $\beta$-D-maltopyranoside (DDM) and Triton X-100 were purchased from Anatrace (USA). The Ethylenediaminetetraacetic acid (EDTA)-free protease inhibitor cocktail came from Roche (Switzerland). PD10 columns and the Sephadex 200 10/300 GL were from GE Healthcare Life Sciences (UK) and Ni-NTA Agarose was from Qiagen (Germany). U- ${ }^{13} \mathrm{C}$ $\mathrm{D}$-glucose and ${ }^{15} \mathrm{~N}$-ammonium chloride were purchased from Cortecnet (France) and Cambridge Isotope Laboratories, Inc. (USA). Phosphatidylcholine (EPC) and phosphatidic acid (EPA) from egg yolk came from Sigma Aldrich (USA). E. coli C41(DE3) competent cells were purchased from Lucigen (USA).

\section{PRODUCTION AND PURIFICATION OF BmrA}

$B m r A$ was expressed from the previously described pET23b $(+)$ bmrA plasmid (Steinfels et al., 2002) in the E. coli strain C41(DE3) (Miroux and Walker, 1996). The resulting protein carries a hexahistidine affinity tag at its $\mathrm{C}$-terminus and it contains three additional amino acid residues in the $\mathrm{N}$-terminus coming from the cloning site (Figure S1). For the preparation of ${ }^{13} \mathrm{C},{ }^{15} \mathrm{~N}$ labeled BmrA, bacteria were grown in M9-type medium (Studier, 2005). Isotope labeling was performed using uniformly $99 \%$ ${ }^{13} \mathrm{C}$-enriched glucose $(2 \mathrm{~g} / \mathrm{L})$ and $98 \%{ }^{15} \mathrm{~N}$-enriched ammonium chloride $(2 \mathrm{~g} / \mathrm{L})$ as sole carbon and nitrogen sources. A $50 \mathrm{~mL}$ ${ }^{13} \mathrm{C},{ }^{15} \mathrm{~N}$-M9-culture was inoculated with a $3 \mathrm{~mL} \mathrm{LB}$ overnight culture that was started from a freshly transformed colony. This pre-culture was incubated at $37^{\circ} \mathrm{C}$ to a maximum optical density at $600 \mathrm{~nm}\left(\mathrm{OD}_{600} \mathrm{~nm}\right)$ of 1.5 and was used to inoculate $150 \mathrm{ml}$ ${ }^{13} \mathrm{C},{ }^{15} \mathrm{~N}-\mathrm{M} 9$ medium to an $\mathrm{OD}_{600} \mathrm{~nm}$ of 0.2 , which was cultured at $25^{\circ} \mathrm{C}$ overnight. The two ${ }^{13} \mathrm{C},{ }^{15} \mathrm{~N}$-M9 pre-cultures were included to slowly adapt the bacteria to the final cultivation conditions. Afterwards the third pre-culture is diluted in $850 \mathrm{~mL}$ fresh ${ }^{13} \mathrm{C},{ }^{15} \mathrm{~N}-\mathrm{M} 9$ medium and incubated at $25^{\circ} \mathrm{C}$, and expression was 
induced with $1 \mathrm{mM}$ IPTG at an $\mathrm{OD}_{600 \mathrm{~nm}}$ between 0.5 and 0.7 . Cells were harvested 5-6h after induction, in the beginning of the stationary growth phase, by centrifugation at $6000 \times \mathrm{g}$.

Membrane fractions were prepared as described (Chami et al., 2002), suspended in buffer A (50 mM Tris- $\mathrm{HCl} \mathrm{pH} 8.0,1 \mathrm{mM}$ EDTA, $300 \mathrm{mM}$ sucrose), frozen in liquid nitrogen, and finally stored at $-80^{\circ} \mathrm{C}$. The purification follows the protocol described (Steinfels et al., 2002) with a few modifications. The membranes were thawed and diluted at $2 \mathrm{mg} / \mathrm{mL}$ protein with the solubilization buffer B: $50 \mathrm{mM}$ Tris- $\mathrm{HCl}$ pH 8.0, $100 \mathrm{mM} \mathrm{NaCl}$, 1\% DDM, $1 \mathrm{mM}$ Dithiothreitol (DTT), 15\% glycerol, $5 \mathrm{mM}$ $\mathrm{MgCl}_{2}$, Benzonase and EDTA-free protease inhibitor cocktail. The suspension was incubated for $1 \mathrm{~h}$ at $4^{\circ} \mathrm{C}$ and the insoluble material was removed by centrifugation at $98,000 \times \mathrm{g}$ for $1 \mathrm{~h}$ at $4^{\circ} \mathrm{C}$.

The solubilization efficiency for BmrA was about $80-90 \%$ (Figure 1A). The solubilized protein was loaded onto a Ni-NTA Agarose gravity column, which was equilibrated with buffer $\mathrm{C}$ (50 mM Tris- $\mathrm{HCl}$ pH 8.0, $100 \mathrm{mM} \mathrm{NaCl}, 15 \%$ glycerol, $0.2 \%$ DTT and $10 \mathrm{mM}$ imidazole), washed successively with buffer $\mathrm{C}$ containing $0.5 \mathrm{M} \mathrm{NaCl}$, with buffer $\mathrm{C}$ alone, buffer $\mathrm{C}$ containing $30 \mathrm{mM}$ imidazole, buffer $\mathrm{C}$ containing $40 \mathrm{mM}$ imidazole and finally eluted with buffer $\mathrm{C}$ containing $250 \mathrm{mM}$ imidazole. The additional purification step with $0.5 \mathrm{M} \mathrm{NaCl}$ was introduced to reduce nucleotide contaminations. The buffer of the eluted protein was exchanged to buffer D ( $50 \mathrm{mM}$ Tris- $\mathrm{HCl}, 100 \mathrm{mM} \mathrm{NaCl}$, $10 \%$ glycerol, $0.2 \%$ DDM, EDTA-free protease inhibitor cocktail) using PD10 desalting columns (Figure 1B). The protein concentration was maintained in all steps at $2-3 \mathrm{mg} / \mathrm{mL}$ to avoid protein aggregation.

For subsequent reconstitution into lipids, BmrA was diluted to a final concentration of $0.2 \mathrm{mg} / \mathrm{mL}$ and $0.05 \%$ DDM. Protein concentration was determined by absorbance at $280 \mathrm{~nm}$. The final preparation was analyzed by analytical size exclusion chromatography (SEC) using a Sephadex 200 10/300 GL column (Figure 1C). SEC was performed using buffer D containing $0.05 \% \mathrm{DDM}$ at a flow rate of $0.3 \mathrm{~mL} / \mathrm{min}$. All purification steps were followed by Coomassie brilliant blue-stained 10\% sodium dodecyl sulfate polyacrylamide gel electrophoresis (SDS-PAGE) (Figure 1). The final yield of BmrA was around $10 \mathrm{mg}$ per liter of culture. The main band on SDS-PAGE was digested by trypsin and analyzed by LC-MS/MS to ensure that it contains exclusively BmrA.

\section{LIPID EXTRACTION FROM B. SUBTILIS}

B. subtilis was cultivated in LB medium (Sigma Aldrich) at $37^{\circ} \mathrm{C}$ for $18 \mathrm{~h}$. The cells were harvested at an $\mathrm{OD}_{600 \mathrm{~nm}}$ of 4 by centrifugation at $6000 \times$ g. Lipid extraction was done as described (Bligh and Dyer, 1959). In short, $10 \mathrm{~g}$ bacterial pellets were suspended in $60 \mathrm{ml}$ chloroform and methanol $(1: 2, \mathrm{v} / \mathrm{v})$. The mixture was stirred for $2 \mathrm{~h}$ at room temperature. Solid particles were removed by filtration. The filtrate was mixed with $20 \mathrm{~mL}$ chloroform and $20 \mathrm{~mL}$ deionized water and extraction was performed for 2 days in a separation funnel. The solvent of the lower phase was removed in a rotary evaporator and by lyophilization. The lipids were stored in chloroform at $-20^{\circ} \mathrm{C}$ for no longer than 1 month. The final lipid amount was about $20 \mathrm{mg}$ per liter of B. subtilis culture.

\section{RECONSTITUTION OF BmrA INTO LIPIDS FROM B. SUBTILIS AND INTO EPC/EPA}

Lipids were solubilized in chloroform and Triton X-100 in methanol. Then, lipid/chloroform and Triton X-100/methanol were mixed in a lipid-detergent ratio 1:10 ( $\mathrm{mol} / \mathrm{mol})$. An average molecular weight of $768 \mathrm{Da}$ was taken as a basis for the calculations for the mixture of egg-L- $\alpha$-phosphatidylcholine (EPC)/ egg-L- $\alpha$-phosphatidic acid (EPA), and $\sim 1000 \mathrm{Da}$ for the B. subtilis lipid extracts (Griffiths and Setlow, 2009). EPC and EPA were used in a ratio 9:1 (w/w) as described (Orelle et al., 2008). Natural lipids were preferred over synthetic lipids, as they display a range of fatty acid chain lengths and degrees of saturation (Avanti Polar Lipids Product Sheet).

The solvents were removed by $\mathrm{N}_{2}$ gas flow, followed by lyophilization for $30 \mathrm{~min}$. The resulting lipid/detergent film was first dissolved in $1 / 2$ final volume deionized $\mathrm{H}_{2} \mathrm{O}$ and afterwards in $1 / 2$ final volume buffer $\mathrm{E}$ (100 mM Tris- $\mathrm{HCl} \mathrm{pH} 8.0,200 \mathrm{mM} \mathrm{NaCl}$, $20 \%$ glycerol) to a final lipid concentration of $5 \mathrm{mg} / \mathrm{mL}$. The lipids were added to the detergent solubilized BmrA $(0.2 \mathrm{mg} / \mathrm{mL})$ to a LPR (lipid-to-protein ratio) of 0.5 , 1, or 2 . Subsequently, the detergents were removed by dialysis with buffer $\mathrm{F}(50 \mathrm{mM}$ Tris- $\mathrm{HCl} \mathrm{pH}$ 8.0, $200 \mathrm{mM} \mathrm{NaCl}, 5 \%$ glycerol, $0.05 \% \mathrm{NaN}_{3}$ ) for 9 days at room temperature. $40 \mathrm{~mL}$ of sample were dialyzed in $5 \mathrm{~L}$ of buffer $\mathrm{J}$ using dialysis tubing with a cut-off of $6-8 \mathrm{kDa}$ (Spectra/Por ${ }^{\circledR}$ Dialysis Membrane, SPECTRUMLABS.COM). To ensure an efficient depletion of detergents, three times the theoretical required quantity of Bio-Beads (SM2, 20-50 mesh; BioRad, USA) was added to the dialysis buffer at the beginning of dialysis and again after 6 days. The calculations were based on the adsorption capacities of $105 \mathrm{mg}$ DDM per $1 \mathrm{~g}$ Bio-beads (Rigaud et al., 1995) and $70 \mathrm{mg}$ Triton X-100 per $1 \mathrm{~g}$ BioBeads (Bio-Rad, user manual). Incorporation of BmrA into lipid membranes was analyzed by centrifugation on sucrose gradient (see below), transmission electron microscopy (TEM) and coomassie brilliant blue stained SDS-PAGE (10\% acrylamide). For analysis by SDS-PAGE, a $100 \mu \mathrm{l}$ sample was centrifuged at $20,000 \times \mathrm{g}, 4^{\circ} \mathrm{C}$ for $30 \mathrm{~min}$. The pellet was resuspended in $100 \mu \mathrm{l}$ of buffer F. The TEM analysis was done by the Center d'Imagerie Quantitative Lyon Est (CIQLE, France) on a TEM JOEL 1400. Samples were negatively stained with $2 \%$ phosphotungstic acid. The protein concentration was determined with BCA Protein Assay Kit from Pierce (USA). A $3.2 \mathrm{~mm}$ NMR rotor (Bruker Biospin) was filled with reconstituted BmrA by centrifugation at $30,000 \times$ g using a custom-made device (Böckmann et al., 2009).

\section{ANALYSIS OF RECONSTITUTED BmrA IN A SUCROSE GRADIENT}

A discontinuous sucrose density gradient was prepared by layering $200 \mu \mathrm{L}$ of $10,20,25,30,35,40,45,50,60$, and $70 \%$ $(\mathrm{w} / \mathrm{v})$ sucrose in $50 \mathrm{mM}$ Tris- $\mathrm{HCl} \mathrm{pH} 8.0,200 \mathrm{mM} \mathrm{NaCl}, 5 \%$ glycerol. A sample volume of $400 \mu \mathrm{L}$ was layered on top of the gradient and centrifuged at $164,000 \times \mathrm{g}$ at the average radius of $91.7 \mathrm{~mm}$ in a Beckman SW $60 \mathrm{Ti}$ rotor during $16 \mathrm{~h}$ at $4^{\circ} \mathrm{C}$. After centrifugation, the different fractions were collected by pipetting and analyzed by SDS-PAGE (10\% acrylamide). 

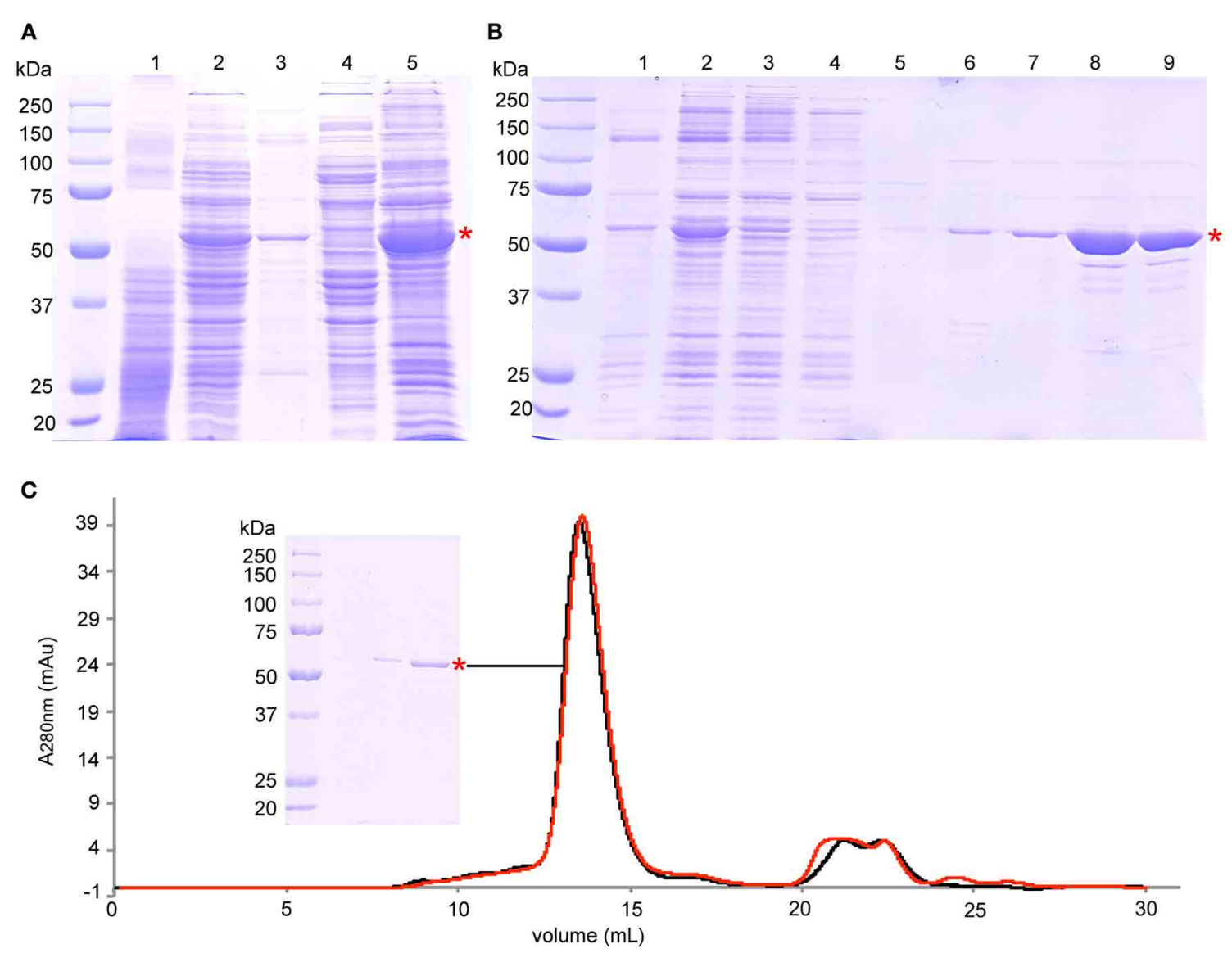

FIGURE 1 | Purification of BmrA. (A) SDS-PAGE analysis of protein expression and membrane preparation: lane 1-cell lysate before induction, lane 2-cell lysate after $6 \mathrm{~h}$ of overexpression, lane 3-pellet after centrifugation at $15,000 \times \mathrm{g}$, lane 4-supernatant after centrifugation at $193,000 \times \mathrm{g}$, lane 5 -isolated membranes after centrifugation at $193,000 \times$ g. (B) SDS-PAGE analysis of protein solubilization and purification steps on Ni-NTA Agarose: lane 1-pellet after solubilization and centrifugation at $98,000 \times \mathrm{g}$, lane 2-supernatant after solubilization and after centrifugation at $98,000 \times g$ that was loaded onto Ni-NTA Agarose, lane 3-flow through of Ni-NTA Agarose gravity column, lane 4-wash step I with buffer $\mathrm{C}(0.5 \mathrm{mM} \mathrm{NaCl}, 10 \mathrm{mM}$ imidazole), lane 5-wash step
II with buffer $\mathrm{C}(0.1 \mathrm{M} \mathrm{NaCl}, 10 \mathrm{mM}$ imidazole), lane 6-wash step III with buffer $\mathrm{C}(0.1 \mathrm{M} \mathrm{NaCl}, 30 \mathrm{mM}$ imidazole), lane 7-wash step IV with buffer $\mathrm{C}(0.1 \mathrm{M} \mathrm{NaCl}, 40 \mathrm{mM}$ imidazole), lane 8-elution with buffer $\mathrm{C}$ (0.1 M NaCl, $250 \mathrm{mM}$ imidazole), lane 9-purified protein after removal of imidazole by PD10 columns. (C) Size exclusion chromatography of the final product after purification (black trace), and after 7 days at room temperature (red trace). SDS-PAGE of the BmrA peak is also shown. The peaks at $21 \mathrm{~mL}$ to $26 \mathrm{~mL}$ correspond mainly to nucleotides with absorption maxima of $\sim 260 \mathrm{~nm}$. BmrA is indicated by a red star. The SDS gels $(10 \%$ acrylamide) were stained with Coomassie brilliant blue.

\section{ATPASE ACTIVITY ASSAY}

For ATPase activity measurements, $4-6 \mu \mathrm{g}$ reconstituted BmrA in $25 \mu \mathrm{l}$ buffer $\mathrm{F}$ were pre-incubated at $37^{\circ} \mathrm{C}$ for $1 \mathrm{~min}$ before $10 \mathrm{mM}$ ATP/10 mM MgCl 2 were added. $0.8 \mathrm{mM}$ ortho-vanadate (Sigma Aldrich) was added $1 \mathrm{~min}$ after activation with $\mathrm{ATP} / \mathrm{MgCl}_{2}$ to inhibit BmrA (Liu et al., 1997). After $4 \mathrm{~min}$, the reaction was stopped by addition of an equal amount of $12 \%$ sodium dodecyl sulfate and the ATP hydrolysis was determined by measuring free Pi (Chifflet et al., 1988).

\section{SOLID-STATE MAS NMR EXPERIMENTS}

All NMR experiments were carried out on a Bruker Biospin AVANCE III spectrometer operating at $800 \mathrm{MHz}{ }^{1} \mathrm{H}$ frequency using a $3.2 \mathrm{~mm}$ triple-resonance $\left({ }^{1} \mathrm{H},{ }^{13} \mathrm{C},{ }^{15} \mathrm{~N}\right)$ E-free probe (Bruker Biospin). Sample temperature was determined using the chemical shift of supernatant water (Böckmann et al., 2009) and was set to $278 \mathrm{~K}$. All experiments were conducted at $17.5 \mathrm{kHz}$ spinning frequency using $90 \mathrm{kHz}$ SPINAL64 (Fung et al., 2000) proton decoupling. The proton and carbon field amplitudes during the ${ }^{1} \mathrm{H}-{ }^{13} \mathrm{C}$ cross-polarization transfer step were around $66 \mathrm{kHz}$ and $50 \mathrm{kHz}$ respectively, using a tangential ramp with a span of $\pm 5 \%$ on the carbon channel. The Dipolar Assisted Rotational Resonance (DARR) (Takegoshi et al., 2001; Morcombe et al., 2005; Scholz et al., 2008) experiment was recorded in 48 scans per increment with a $20 \mathrm{~ms}$ mixing time. Acquisition times were $15 \mathrm{~ms}$ in $t_{2}$ and $10 \mathrm{~ms}$ in $t_{1}$, and the interscan delay was $2 \mathrm{~s}$, corresponding to a total measurement time of $50 \mathrm{~h}$. Spectra were processed with Topspin using a shifted $\cos ^{2}$ function and analyzed using CcpNmr Analysis (Stevens et al., 2011). 


\section{RESULTS AND DISCUSSION \\ BmrA IS PRODUCED IN HIGH YIELD AND HIGH PURITY}

For production of isotopically labeled BmrA required for NMR studies, we adapted the protocol (Steinfels et al., 2002) for overexpression of the protein in minimal medium. Under these conditions, the yield for BmrA was $10 \mathrm{mg}$ of purified protein per liter of culture. The results of protein production, membrane preparation and purification, analyzed by SDS-PAGE, are shown in Figure 1. BmrA could be solubilized efficiently from the E. coli membranes by DDM (up to $80 \%$ ). Protein loss was successfully avoided by ensuring that the high transient protein concentrations during purification were accommodated by an increased detergent concentration during affinity chromatography. It was however important that, before reconstitution into lipid membranes, the detergent concentration was reduced, to avoid even longer dialysis times. The final product did not contain BmrA aggregates and was stable at room temperature over at least 7 days, as shown by analytical size exclusion chromatography (Figure 1C). The main band on SDS-PAGE is exclusively composed of BmrA from B. subtilis as confirmed by mass spectrometry analysis.

\section{SLOW DETERGENT REMOVAL BY DIALYSIS YIELDS HOMOGENOUS BmrA SAMPLES}

BmrA can be inserted in lipid membranes of different composition (EPC/EPA, DMPC, DOPC and E. coli lipids) and form ring-shaped or tubular superstructures (Orelle et al., 2008; Dezi et al., 2011; Galián et al., 2011; Fribourg et al., 2014). A recent 3D cryo-electron reconstruction of $\mathrm{BmrA}$ in this ring-shaped structures clearly shows that the homodimer is embedded in a lipid bilayer. The NBDs are located on the outside of the ring. The 3D model of the apo-BmrA shows an open inward-facing conformation (Fribourg et al., 2014). The formation of rings vs. tubes depends on the lipid-to-detergent ratio in the sample. On further detergent removal, the rings tend to stack together forming non-crystalline tubular structures (Chami et al., 2002; Fribourg et al., 2014). As BmrA is a protein from B. subtilis, we tried B. subtilis lipid extract to prepare BmrA in a lipid environment as close as possible to the native conditions. The cytoplasmic membrane of B. subtilis is mainly composed of phosphatidylglycerol (23\%), cardiolipin (46\%), phosphatidylethanolamine (14\%) and diglucosyl diacylglycerol (17\%) (Griffiths and Setlow, 2009). An EPC/EPA mixture at 9:1 (w/w) was used for comparison, as it has already been successfully used for cryo-EM studies (Chami et al., 2002; Fribourg et al., 2014). For reconstitution of BmrA in lipids, the detergent-solubilized protein is mixed with the detergent-solubilized lipids (Rigaud et al., 1995). While in the previously published protocol [used for the preparation of electron-microscopy (EM) samples], the detergent removal was done by subsequent addition of Bio-Beads directly to the protein-lipid-detergent mixture (Orelle et al., 2008), the use of this protocol resulted in about $50 \%$ loss of protein using a LPR of 0.5 . This is likely due to a sudden and inhomogeneous removal of detergents by Bio-Beads, leading to protein aggregation. We thus used dialysis for detergent removal, with Bio-Beads added in the dialysis buffer outside the dialyzed sample in order to deplete the detergent. This procedure yielded homogenous samples displayed in the EM micrographs in Figures 2A,C. The samples contained mainly non-crystalline supra-molecular tubular structures with B. subtilis lipids as well as with EPC/EPA, consistent with the previous studies (Orelle et al., 2008; Dezi et al., 2011; Galián et al., 2011; Fribourg et al., 2014). 2D crystals of BmrA have been described in the literature only for the protein in the ADP-Vi trapped state (Fribourg et al., 2014).

\section{BmrA IS STABLE WHEN RECONSTITUTED IN NATIVE B. SUBTILIS LIPIDS}

The SDS-PAGE gels of reconstituted BmrA in B. subtilis lipids and in EPC/EPA lipids are shown in Figure 3A. After 9 days of membrane reconstitution, the protein is mainly observed in the pellet, for both lipid mixtures. Figure 3B shows the evolution of the sample with time, an important parameter for solid-state NMR samples, which are often used over long time periods. One can see that the preparation in B. subtilis lipids, when kept at room temperature, is stable over 2 weeks and free of degradation. In EPC/EPA (9:1), the intensity of the BmrA band decreases over time, indicating a slow degradation. An analysis by EM of the evolution of the samples in B. subtilis lipids (Figures 2A, B) and EPC/EPA (9:1) (Figures 2C,D) confirms that the preparation in the native lipids is stable over 2 weeks at room temperature, while the EM after 15 days in EPC/EPA (9:1) shows the loss of tubular structures and the appearance of aggregated protein (Figure 2D).

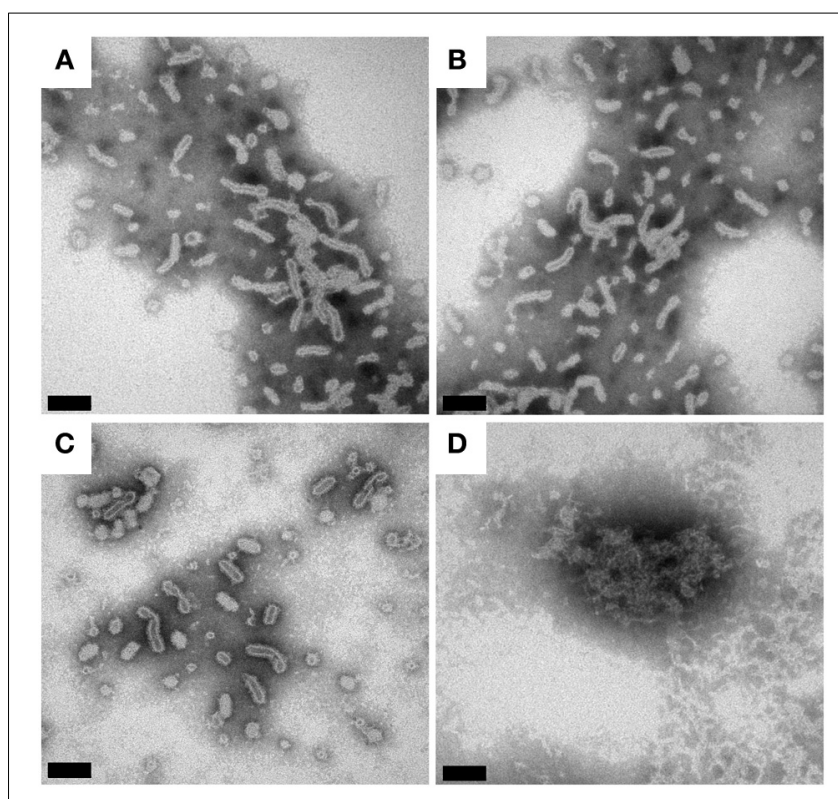

FIGURE 2 | Transmission electron micrographs of BmrA in B. subtilis lipids and EPC/EPA (9:1). The protein reconstituted into a lipid bilayer forms ring- and tubular structures (Orelle et al., 2008). (A) BmrA in B. subtilis lipids 1 day after dialysis. (B) BmrA in B. subtilis lipids 15 days after dialysis (stored at room temperature). (C) BmrA in EPC/EPA 1 day after dialysis. (D) BmrA in EPC/EPA 15 days after dialysis (stored at room temperature), showing the loss of the tubular structure and protein aggregation indicating that, in contrast to the sample in native lipids, the sample is not stable in EPC/EPA for long-term storage. The samples were negatively stained with $2 \%$ phosphotungstic acid. The bars represent $100 \mathrm{~nm}$ (A-C) and $50 \mathrm{~nm}$ (D). 


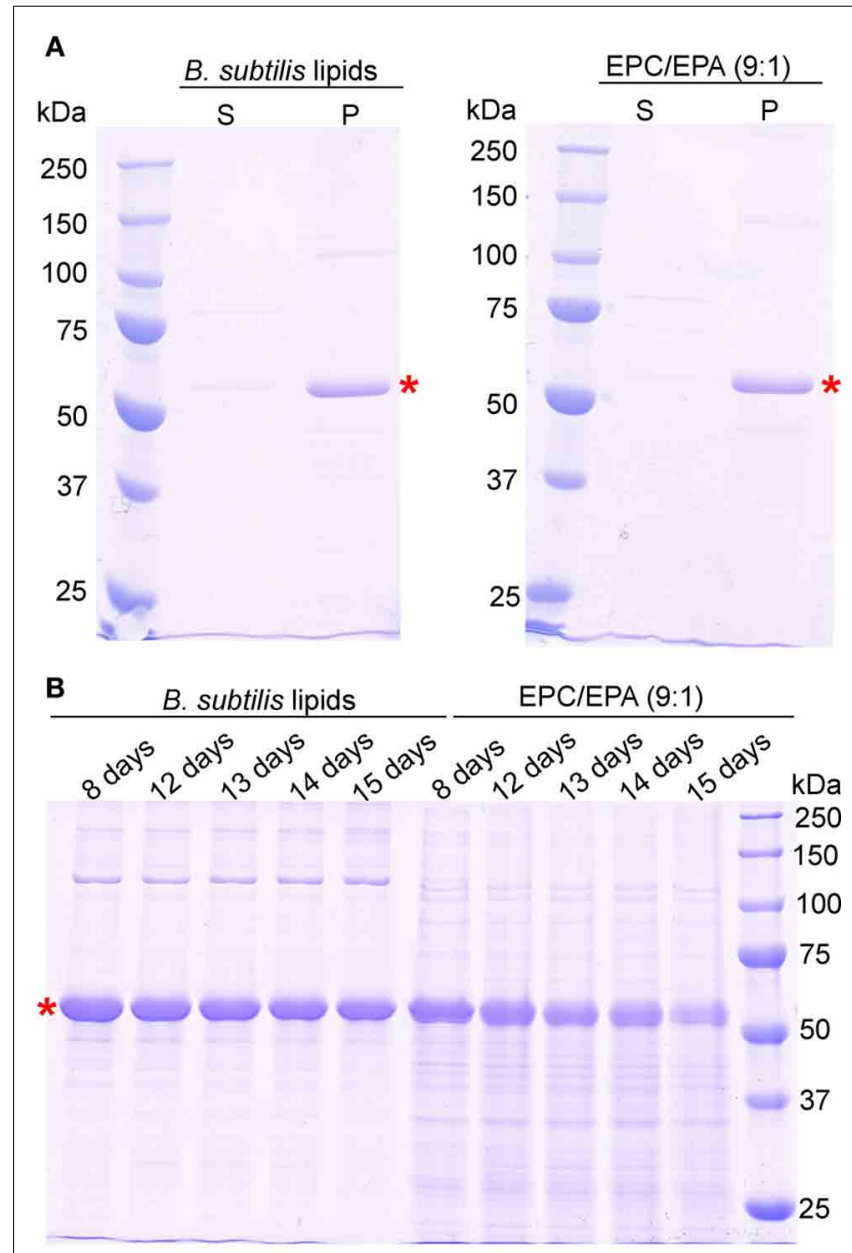

C

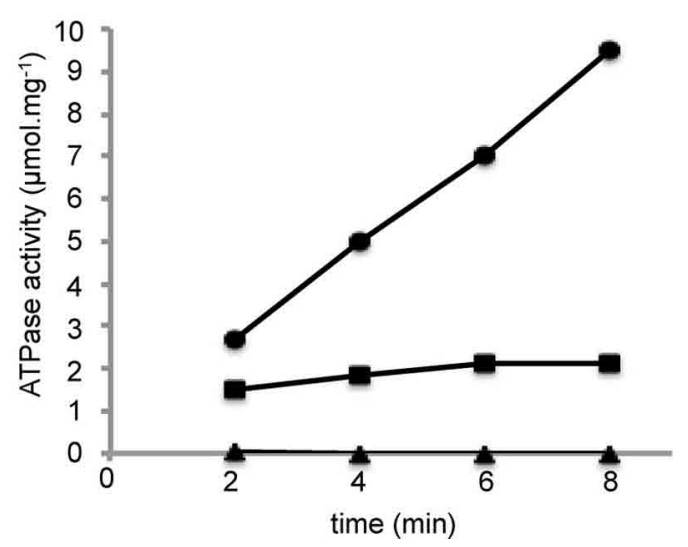

FIGURE 3 | Reconstitution and stability of BmrA in B. subtilis lipids and EPC/EPA (9:1) analyzed with SDS-PAGE. (A) After 9 days of dialysis, an aliquot was centrifuged at $20000 \times \mathrm{g}$ for the analysis of the supernatant (S) and the pellet (P). (B) For analysis of the stability of BmrA in the different lipid environments, after dialysis protein-lipid structures were incubated at room temperature and aliquots were analyzed by SDS-PAGE at the indicated times. BmrA is indicated by a red star. The SDS-PAGE gels (10\% acrylamide) were stained with Coomassie brilliant blue. (C) Typical results for ATP hydrolysis by BmrA (dots) and its efficient inhibition by ortho-vanadate (rectangles). As a control BmrA was measured without additives (triangles). Samples were analyzed after 2, 4, 6, and 8 min after addition of $\mathrm{ATP} / \mathrm{MgCl}_{2}$.

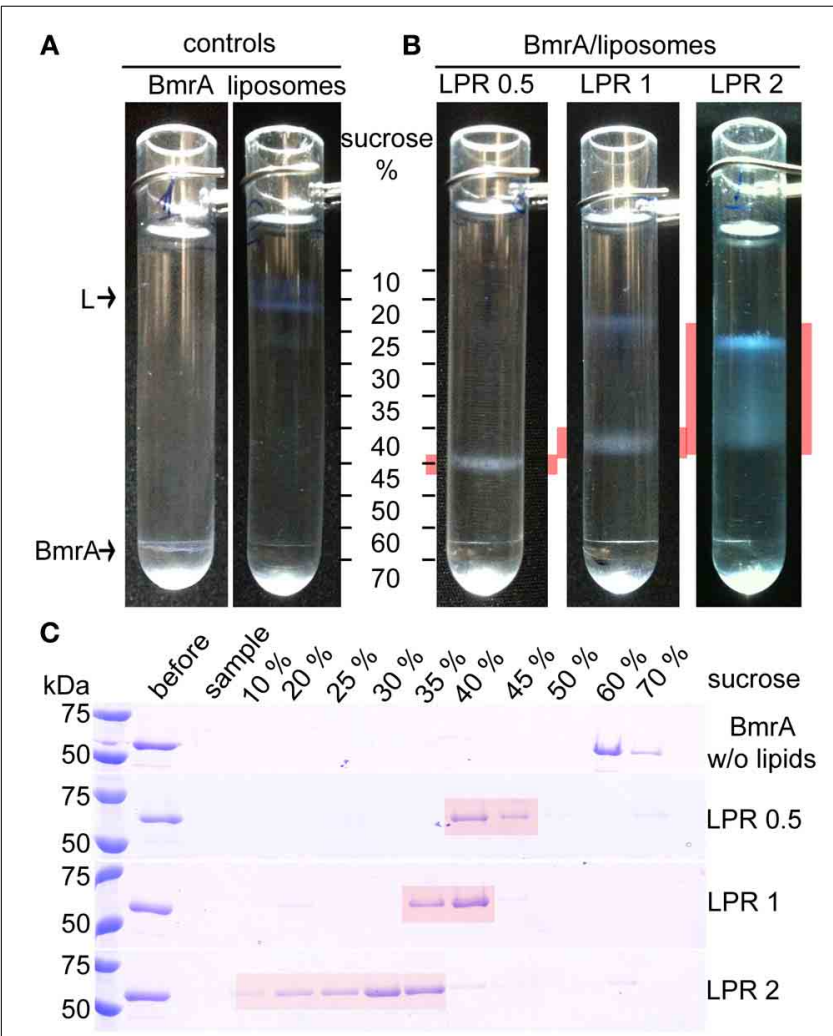

FIGURE 4 | Analysis of BmrA reconstitution in B. subtilis lipids with different LPRs by sucrose gradient centrifugation. (A) Controls: Sucrose gradients of BmrA dialyzed in the absence of lipids in order to identify the densities of aggregated BmrA (left) and of lipids without protein (right, labeled by an " $\mathrm{L}$ "). (B) Sucrose gradients of BmrA reconstituted in $B$. subtilis lipids using LPR 0.5, 1 and 2. Gradient layers containing BmrA in lipids are highlighted in red. (C) The layers $(\sim 200 \mu)$ of the gradients were analyzed by SDS-PAGE. The first two lanes after the protein ladder show the sample before centrifugation (before) and the sample-layer (sample) after centrifugation. Given concentrations correspond to sucrose concentrations before centrifugation.

The higher stability of tubes containing BmrA in B. subtilis lipids might arise from their lipid composition. The same protein stability would possibly be achieved as well using more complex lipid mixtures from natural sources or synthetic lipids with a similar composition.

Importantly, the NMR samples prepared using B. subtilis lipids are stable over several months (see below). As a further criterion for sample quality we routinely address the ATPase activity of the preparations. The presented protocol for reconstitution of BmrA in $B$. subtilis lipids with a LPR of 0.5 gives here a highly reproducible ATPase activity of $1.3 \pm 0.1 \mu$ mol hydrolyzed ATP per minute and $\mathrm{mg}$ BmrA, that can be inhibited by ortho-vanadate to $95 \pm 8 \%$ (Figure 3C). These results are comparable to previously published data for ring and tube like structures of BmrA in lipid membranes (Orelle et al., 2008).

\section{A LIPID-TO-PROTEIN RATIO OF 0.5 IS OPTIMAL}

Measuring the protein concentration before and after reconstitution reveals that when a LPR of 0.5 is used, about $90 \%$ of the 
protein is reconstituted into lipids, both when $B$. subtilis lipids or EPC/EPA were used. This is also shown in the SDS-PAGE gel in Figure 3A, where the majority of the protein is observed in the pellet. Higher LPRs were tested to reduce protein loss and obtain complete insertion into lipid membranes, but such conditions resulted in NMR samples with less signal/noise. Besides the increased amount of lipids, the loss also resulted from an increased sample viscosity, which yielded on rotor packing a gluey, very hydrated pellet. Using a sucrose density gradient, we visualized the fractions containing only lipids (in absence of protein), tube-like protein-lipid structures and protein aggregates, as these species show a different sedimentation behavior. Figure 4 shows the sucrose density gradient analysis, comparing BmrA reconstituted in B. subtilis lipids at LPR of $0.5,1$ and 2 . The first centrifugation tube (Figure 4A) shows a BmrA-withoutlipids control, which aggregates upon detergent removal and is found between 60 and $70 \%$ sucrose, as checked by SDS-PAGE (Figure 4C, top). The second centrifugation tube (Figure 4A) shows a lipids-without-protein control, found around 10-20\% sucrose. In Figure 4B, lipid-inserted protein can be seen as a white band in-between these bands in the control experiment. At an LPR of 0.5 , only lipid-protein structures are observed, with a narrow band and a homogenous density around 40-45\% sucrose. Using a LPR of 1, one can clearly observe lipids containing almost no protein around $10-20 \%$ sucrose, and a broader band of supra-molecular structures around 35-40\% sucrose, indicating a heterogeneous composition. By increasing the LPR to 2, a wider distribution of this band appears between 10 and
$40 \%$ sucrose, with protein concentration increasing from top to bottom (Figure 4C, bottom).

\section{OPTIMIZED BmrA SAMPLES YIELD HIGH-QUALITY SOLID-STATE NMR SPECTRA}

To summarize the optimal preparation conditions used for the NMR sample: the protein was reconstituted in B. subtilis lipids, starting from $0.2 \mathrm{mg} / \mathrm{mL}$ BmrA in $0.05 \%$ DDM, using a LPR of 0.5 , and detergent removal was conducted by dialysis with BioBeads added to the buffer, for 9 days. A two-dimensional ${ }^{13} \mathrm{C}-{ }^{13} \mathrm{C}$ DARR correlation spectrum of the resulting BmrA sample is shown in Figure 5A. The spectrum displays narrow resonance lines for isolated peaks, and a chemical-shift dispersion typical for a well-folded protein, even if the large number of signals from the 589 amino-acid-residue protein results in heavy resonance overlap. Cross-peaks from many individual atom pairs can be detected. Isolated resonances typically exhibit a line width of $0.5 \mathrm{ppm}$, and a signal-to-noise ratio of 8.75 , as shown for example for cross peaks stemming from Ala $\mathrm{C} \alpha-\mathrm{C} \beta$ (Figure 5C). The signal-to-noise ratio in this $50 \mathrm{~h}$ experiment is excellent in the sense that the signal-to-noise per unit time of an isolated residue (the Ala peak highlighted in Figure 5C) is, taking into account the size of the protein but not yet the dilution by lipids, within a factor of 2 of the one of a microcrystalline ubiquitin sample, indicating a good rotor filling and a protein state that shows efficient cross polarization and DARR polarization transfer.

The chemical shift is sensitive to the secondary structure; it enables to differentiate $\mathrm{C} \alpha-\mathrm{C} \beta$ cross-peaks originating from
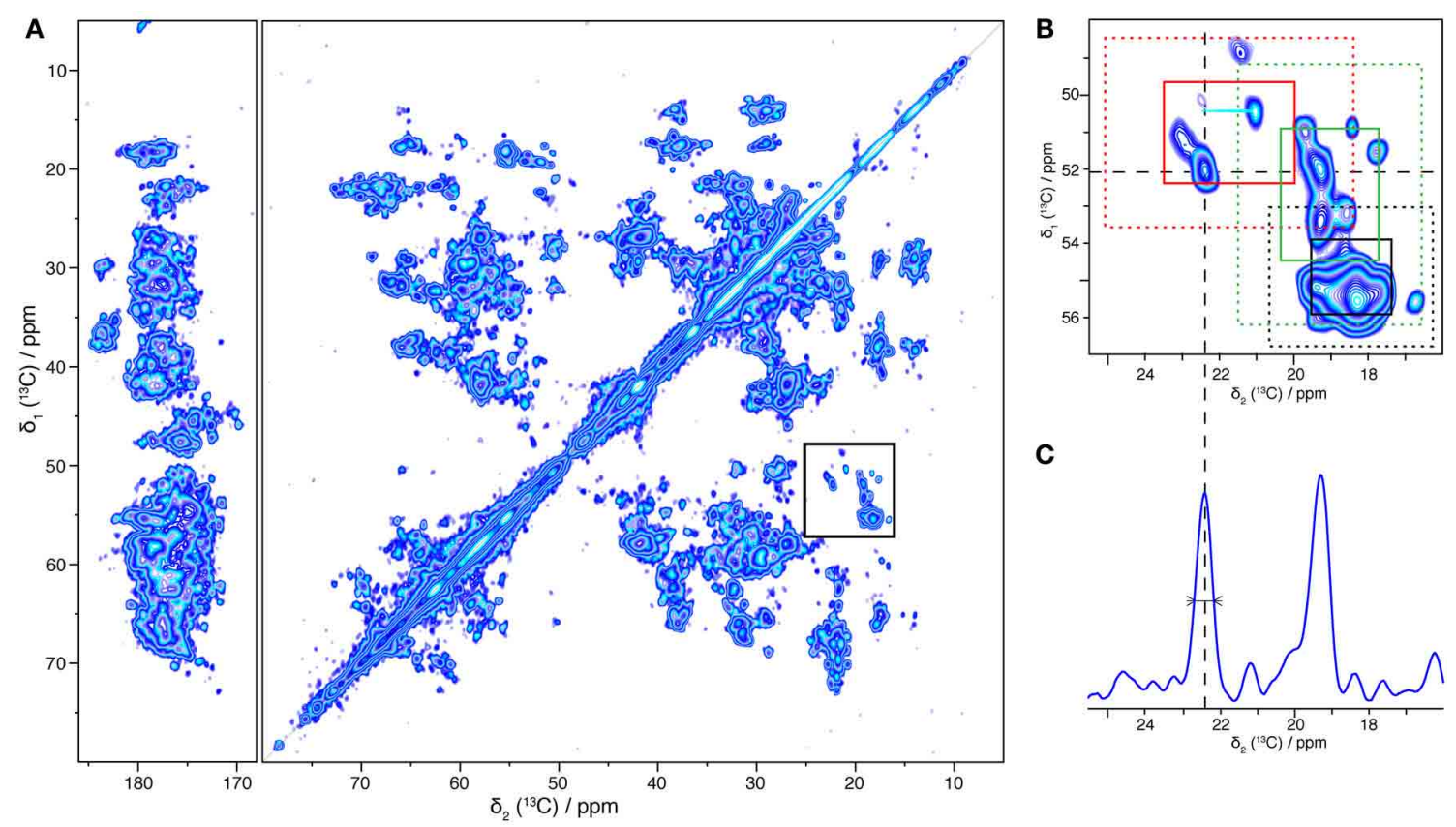

FIGURE $5 \mid{ }^{13} \mathrm{C}-{ }^{13} \mathrm{C}$ two-dimensional solid-state NMR correlation experiment (DARR, $20 \mathrm{~ms}$ ). (A) Overview spectrum with aliphatic and carbonyl regions. (B) Alanine region. Regions typical for $\beta$-sheet, $\alpha$-helical and coil alanine signals are indicated respectively by red, black and green rectangles: solid lines correspond to the mean value $+/$ - standard deviation and dashed lines to the mean value $+/-2$ times the standard deviation (Wang and Jardetzky, 2002). (C) 1D trace taken at $52.1 \mathrm{ppm}$, the linewidth at half height is $0.5 \mathrm{ppm}$. 


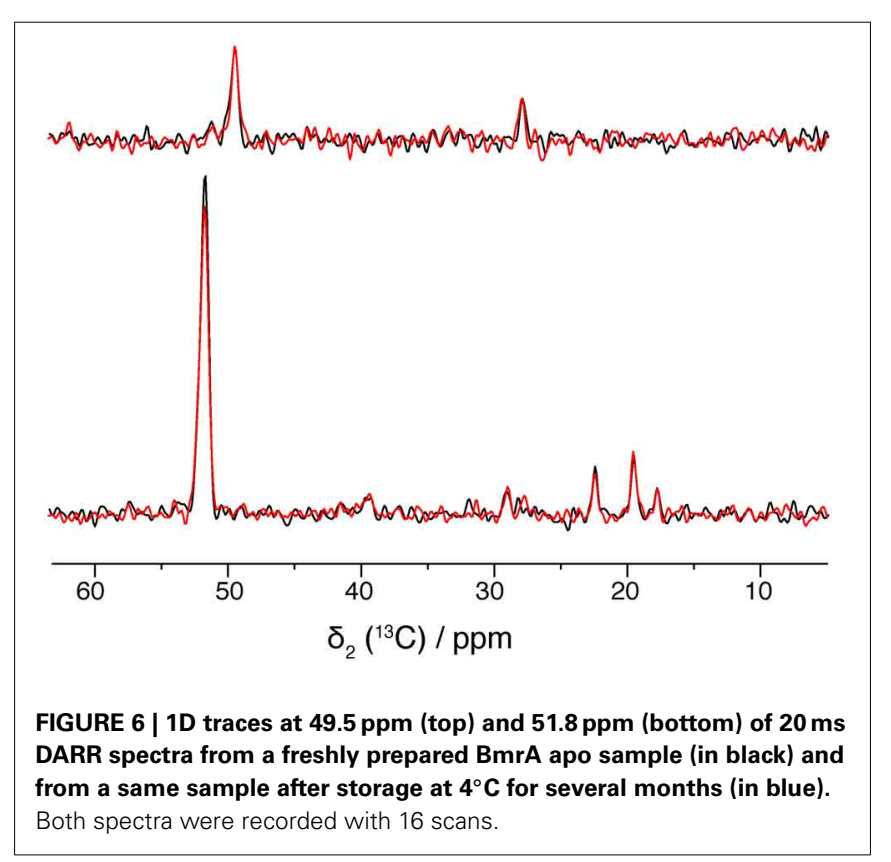

$\alpha$-helices, $\beta$-sheets, and coils. The overall distribution, for the example of alanine chemical shifts, is shown in Figure 5B. Regions typical for alanines in $\alpha$-helices, coils and $\beta$-sheets (Wang and Jardetzky, 2002) are indicated as red, green and black rectangles, respectively. The distribution suggests that BmrA shows a secondary structure organization similar to that described for MsbA in its apo form (PDB ID 3B5W). Indeed, a BmrA model built by homology from MsbA (Do Cao et al., 2009) predicts 30 alanine residues in $\alpha$-helices ( 20 from the TMD and 10 from the $\mathrm{NBD}$ ), 2 in $\beta$-sheet (from the NBD) and 13 in coils (4 from the TMD and 9 from the NBD). Figure 5B clearly shows, besides an intense $\alpha$-helical cross signal, alanine residues in $\beta$-sheet and coil conformation, which should mostly stem from the nucleotidebinding domain. This clearly indicates that both the TMD and the NBD are visible in this spectrum.

Solid-state NMR requires high sample stability, as spectra are often measured over several days or weeks at temperatures above $0^{\circ} \mathrm{C}$. Figure 6 compares spectra of freshly prepared $\mathrm{BmrA}$ and a sample after storage at $4^{\circ} \mathrm{C}$ for several months. The $2 \mathrm{D}$ spectrum shows identical $2 \mathrm{D}{ }^{13} \mathrm{C}-{ }^{13} \mathrm{C}$ correlations, as well as same line-widths, as shown in the $1 \mathrm{D}$ traces in Figure 6. It is worth mentioning as well that the sample preparation yields excellent reproducibility, as spectra from different protein/lipid preparations at different points in time display the same fingerprint.

\section{CONCLUSION}

We report here NMR-scale expression and lipid reconstitution of the B. subtilis $\mathrm{ABC}$ transporter $\mathrm{BmrA}$ leading to a lipid-inserted sample of uniformly $\left[{ }^{13} \mathrm{C},{ }^{15} \mathrm{~N}\right]$ enriched BmrA. The preparation yields narrow resonance lines in the NMR-spectra rivaling microcrystalline preparations (McDermott et al., 2000). The excellent quality of the NMR spectra is a good indicator for a structurally homogeneous membrane-insertion of the protein. Our results demonstrate the feasibility of studying $\mathrm{BmrA}$, and related membrane proteins, by solid-state NMR to obtain site-resolved information about structural and dynamic features of membrane transport proteins in different states (open, closed, drug-bound), even if the de novo structure determination of a protein of this size is still extremely challenging. BmrA is one of the largest proteins studied today by solid-state NMR, and has a typical size encountered for most membrane proteins. We are therefore very optimistic about the further prospects for solid-state NMR of membrane proteins in close-to-natural lipid environment.

\section{ACKNOWLEDGMENTS}

This work was supported by the Center National de la Recherche Scientifique, the ETH Zurich, and the Swiss National Science Foundation (Grant 200020_124611). We acknowledge support from the Partenariat Hubert Curien Germaine de Staël and from the European Commission under the Seventh Framework Programme (FP7), contract Bio-NMR 261863. The EM was done in the Center d'Imagerie Quantitative Lyon Est (CIQLE, France). The mass spectrometry was done by the Center Commun de Micro-analyse des Protéines (IBCP, Lyon, France). Financial support from the TGE RMN THC Fr3050 is gratefully acknowledged.

\section{SUPPLEMENTARY MATERIAL}

The Supplementary Material for this article can be found online at: http://www.frontiersin.org/journal/10.3389/fmolb.2014.000 05/abstract

\section{REFERENCES}

Agarwal, V., Fink, U., Schuldiner, S., and Reif, B. (2007). MAS solid-state NMR studies on the multidrug transporter EmrE. Biochim. Biophys. Acta 1768, 3036-3043. doi: 10.1016/j.bbamem.2007.09.012

Aller, S. G., Yu, J., Ward, A., Weng, Y., Chittaboina, S., Zhuo, R., et al. (2009). Structure of P-glycoprotein reveals a molecular basis for poly-specific drug binding. Science 323, 1718-1722. doi: 10.1126/science.1168750

Andronesi, O. C., Becker, S., Seidel, K., Heise, H., Young, H. S., and Baldus, M. (2005). Determination of membrane protein structure and dynamics by magicangle-spinning solid-state NMR spectroscopy. JACS 127, 12965-12974. doi: 10.1021/ja0530164

Barbet-Massin, E., Ricagno, S., Lewandowski, J. R., Giorgetti, S., Bellotti, V., Bolognesi, M., et al. (2010). Fibrillar vs. crystalline full-length beta-2microglobulin studied by high-resolution solid-state NMR spectroscopy. J. Am. Chem. Soc. 132, 5556-5557. doi: 10.1021/ja1002839

Barends, T. R. M., Foucar, L., Botha, S., Doak, R. B., Shoeman, R. L., Nass, K., et al. (2014). De novo protein crystal structure determination from X-ray freeelectron laser data. Nature 505, 244-247. doi: 10.1038/nature12773

Becker-Baldus, J., and Glaubitz, C. (2014). Symmetrically asymmetric: EmrE seen from the NMR perspective. Chembiochem 17, 249-272. doi: 10.1007/978-3-64253839-1_11

Bhate, M. P., Wylie, B. J., Tian, L., and McDermott, A. E. (2010). Conformational dynamics in the selectivity filter of KcsA in response to potassium ion concentration. J. Mol. Biol. 401, 155-166. doi: 10.1016/j.jmb.2010.06.031

Bligh, E. G., and Dyer, W. J. (1959). A rapid method of total lipid extraction and purification. Can. J. Biochem. Physiol. 37, 911-917. doi: 10.1139/o59-099

Böckmann, A. (2008). 3D Protein structures by solid-state NMR spectroscopy: ready for high resolution. Angew. Chem. Int. Ed Engl. 47, 6110-6113. doi: 10.1002/anie.200801352

Böckmann, A., Gardiennet, C., Verel, R., Hunkeler, A., Loquet, A., Pintacuda, G., et al. (2009). Characterization of different water pools in solid-state NMR protein samples. J. Biomol. NMR 45, 319-327. doi: 10.1007/s10858-009-9374-3

Böckmann, A., and Meier, B. H. (2010). Prions: En route from structural models to structures. Prion 4, 72-79. doi: 10.4161/pri.4.2.11963

Cady, S. D., Schmidt-Rohr, K., Wang, J., Soto, C. S., DeGrado, W. F., and Hong, M. (2010). Structure of the amantadine binding site of influenza M2 proton channels in lipid bilayers. Nature 463, 689-692. doi: 10.1038/nature08722 
Chami, M., Steinfels, E., Orelle, C., Jault, J.-M., Di Pietro, A., Rigaud, J.-L., et al. (2002). Three-dimensional structure by cryo-electron microscopy of YvcC, an homodimeric ATP-binding cassette transporter from Bacillus subtilis1. J. Mol. Biol. 315, 1075-1085. doi: 10.1006/jmbi.2001.5309

Chifflet, S., Torriglia, A., Chiesa, R., and Tolosa, S. (1988). A method for the determination of inorganic phosphate in the presence of labile organic phosphate and high concentrations of protein: application to lens ATPases. Anal. Biochem. 168, 1-4. doi: 10.1016/0003-2697(88)90002-4

Claramunt, R. M., Pérez-Torralba, M., María, D. S., Sanz, D., Elena, B., Alkorta, I., et al. (2010). 15N-15N spin-spin coupling constants through intermolecular hydrogen bonds in the solid state. J. Magn. Reson. 206, 274-279. doi: 10.1016/j.jmr.2010.07.015

Comellas, G., Lemkau, L. R., Nieuwkoop, A. J., Kloepper, K. D., Ladror, D. T., Ebisu, R., et al. (2011). Structured regions of $\alpha$-synuclein fibrils include the early-onset parkinson's disease mutation sites. J. Mol. Biol. 411, 881-895. doi: 10.1016/j.jmb.2011.06.026

Cross, T. A., Ekanayake, V., Paulino, J., and Wright, A. (2014). Journal of magnetic resonance. J. Magn. Reson. 239, 100-109. doi: 10.1016/j.jmr.2013.12.006

Cukkemane, A., Nand, D., Gradmann, S., Weingarth, M., Kaupp, U. B., and Baldus, M. (2012). Solid-state NMR [13C,15N] resonance assignments of the nucleotide-binding domain of a bacterial cyclic nucleotide-gated channel. Biomol. NMR Assign. 6, 225-229. doi: 10.1007/s12104-012-9363-4

Dalmas, O., Orelle, C., Foucher, A.-E., Geourjon, C., Crouzy, S., Di Pietro, A., et al. (2005). The Q-loop disengages from the first intracellular loop during the catalytic cycle of the multidrug ABC transporter BmrA. J. Biol. Chem. 280, 36857-36864. doi: 10.1074/jbc.M503266200

Das, B. B., Zhang, H., and Opella, S. J. (2014). Dipolar Assisted Assignment Protocol (DAAP) for MAS solid-state NMR of rotationally aligned membrane proteins in phospholipid bilayers. J. Magn. Reson. 242, 224-232. doi: 10.1016/j.jmr.2014.02.018

Das, N., Murray, D. T., and Cross, T. A. (2013). Lipid bilayer preparations of membrane proteins for oriented and magic-angle spinning solid-state NMR samples. Nat. Protoc. 8, 2256-2270. doi: 10.1038/nprot.2013.129

Dawson, R. J. P., and Locher, K. P. (2006). Structure of a bacterial multidrug ABC transporter. Nature 443, 180-185. doi: 10.1038/nature05155

Dawson, R. J. P., and Locher, K. P. (2007). Structure of the multidrug ABC transporter Sav1866 from Staphylococcus aureus in complex with AMP-PNP. FEBS Lett. 581, 935-938. doi: 10.1016/j.febslet.2007.01.073

Debelouchina, G. T., Bayro, M. J., van der Wel, P. C. A., Caporini, M. A., Barnes, A. B., Rosay, M., et al. (2010). Dynamic nuclear polarization-enhanced solidstate NMR spectroscopy of GNNQQNY nanocrystals and amyloid fibrils. Phys. Chem. Chem. Phys. 12, 5911-5919. doi: 10.1039/c003661g

Dezi, M., Fribourg, P.-F., Cicco, A. D., Jault, J.-M., Chami, M., and Lévy, D. (2011). Binding, reconstitution and 2D crystallization of membrane or soluble proteins onto functionalised lipid layer observed in situ by reflected light microscopy. J. Struct. Biol. 174, 307-314. doi: 10.1016/j.jsb.2010.12.001

Do Cao, M.-A., Crouzy, S., Kim, M., Becchi, M., Cafiso, D. S., Di Pietro, A., et al. (2009). Probing the conformation of the resting state of a bacterial multidrug ABC transporter, BmrA, by a site-directed spin labeling approach. Protein Sci. 18, 1507-1520. doi: 10.1002/pro.141

Emami, S., Fan, Y., Munro, R., Ladizhansky, V., and Brown, L. S. (2013) Yeast-expressed human membrane protein aquaporin-1 yields excellent resolution of solid-state MAS NMR spectra. J. Biomol. NMR 55, 147-155. doi: 10.1007/s10858-013-9710-5

Ernst, R., Kueppers, P., Stindt, J., Kuchler, K., and Schmitt, L. (2010). Multidrug efflux pumps: substrate selection in ATP-binding cassette multidrug efflux pumps-first come, first served? FEBS J. 277, 540-549. doi: 10.1111/j.17424658.2009.07485.x

Etzkorn, M., Kneuper, H., Dünnwald, P., Vijayan, V., Krämer, J., Griesinger, C., et al. (2008). Plasticity of the PAS domain and a potential role for signal transduction in the histidine kinase DcuS. Nat. Struct. Mol. Biol. 15, 1031-1039. doi: 10.1038/nsmb.1493

Ferguson, N., Becker, J., Tidow, H., Tremmel, S., Sharpe, T. D., Krause, G., et al. (2006). General structural motifs of amyloid protofilaments. Proc. Natl. Acad. Sci. U.S.A. 103, 16248-16253. doi: 10.1073/pnas.0607815103

Fribourg, P.-F., Chami, M., Sorzano, C. O. S., Gubellini, F., Marabini, R., Marco, S., et al. (2014). 3D cryo-electron reconstruction of BmrA, a bacterial multidrug $\mathrm{ABC}$ transporter in an inward-facing conformation and in a lipidic environment. J. Mol. Biol. 426, 2059-2069. doi: 10.1016/j.jmb.2014.03.002
Fung, B. M., Khitrin, A. K., and Ermolaev, K. (2000). An improved broadband decoupling sequence for liquid crystals and solids. J. Magn. Reson. 142, 97-101. doi: 10.1006/jmre.1999.1896

Galián, C., Manon, F., Dezi, M., Torres, C., Ebel, C., Lévy, D., et al. (2011). Optimized purification of a heterodimeric ABC transporter in a highly stable form amenable to 2-D crystallization. PLoS ONE 6:e19677. doi: 10.1371/journal.pone.0019677

Gayen, A., Banigan, J. R., and Traaseth, N. J. (2013). Ligand-induced conformational changes of the multidrug resistance transporter EmrE probed by oriented solid-state NMR spectroscopy. Angew. Chem. Int. Ed. 52, 10321-10324. doi: 10.1002/anie.201303091

Griffiths, K. K., and Setlow, P. (2009). Effects of modification of membrane lipid composition on Bacillus subtilis sporulation and spore properties. J. Appl. Microbiol. 106, 2064-2078. doi: 10.1111/j.1365-2672.2009.04176.x

Heise, H., Luca, S., de Groot, B. L., Grubmüller, H., and Baldus, M. (2005). Probing conformational disorder in neurotensin by two-dimensional solid-state NMR and comparison to molecular dynamics simulations. Biophys. J. 89, 2113-2120. doi: 10.1529/biophysj.105.059964

Hellmich, U. A., Lyubenova, S., Kaltenborn, E., Doshi, R., van Veen, H. W., Prisner, T. F., et al. (2012). Probing the ATP hydrolysis cycle of the ABC multidrug transporter LmrA by pulsed EPR spectroscopy. J. Am. Chem. Soc. 134, 5857-5862. doi: $10.1021 / \mathrm{ja} 211007 \mathrm{t}$

Helmus, J. J., Surewicz, K., Surewicz, W. K., and Jaroniec, C. P. (2010). Conformational flexibility of Y145Stop human prion protein amyloid fibrils probed by solid-state nuclear magnetic resonance spectroscopy. J. Am. Chem. Soc. 132, 2393-2403. doi: 10.1021/ja909827v

Higgins, C. F. (1992). ABC transporters: from microorganisms to man. Annu. Rev. Cell Biol. 8, 67-113. doi: 10.1146/annurev.cb.08.110192.000435

Higman, V. A., Flinders, J., Hiller, M., Jehle, S., Markovic, S., Fiedler, S., et al. (2009). Assigning large proteins in the solid state: a MAS NMR resonance assignment strategy using selectively and extensively 13C-labelled proteins. J. Biomol. NMR 44, 245-260. doi: 10.1007/s10858-009-9338-7

Hiller, M., Krabben, L., Vinothkumar, K. R., Castellani, F., van Rossum, B.-J., Kühlbrandt, W., et al. (2005). Solid-state magic-angle spinning NMR of outermembrane protein G from Escherichia coli. Chembiochem 6, 1679-1684. doi: 10.1002/cbic. 200500132

Hohl, M., Briand, C., Grütter, M. G., and Seeger, M. A. (2012). Crystal structure of a heterodimeric ABC transporter in its inward-facing conformation. Nat. Struct. Mol. Biol. 19, 395-402. doi: 10.1038/nsmb.2267

Holland, I. B., and Blight, M. A. (1999). ABC-ATPases, adaptable energy generators fuelling transmembrane movement of a variety of molecules in organisms from bacteria to humans. J. Mol. Biol. 293, 381-399. doi: 10.1006/jmbi.1999.2993

Hollenstein, K., Dawson, R. J. P., and Locher, K. P. (2007). Structure and mechanism of ABC transporter proteins. Curr. Opin. Struct. Biol. 17, 412-418. doi: 10.1016/j.sbi.2007.07.003

Jehle, S., Rajagopal, P., Bardiaux, B., Markovic, S., Kühne, R., Stout, J. R., et al. (2010). Solid-state NMR and SAXS studies provide a structural basis for the activation of alphaB-crystallin oligomers. Nat. Struct. Mol. Biol. 17, 1037-1042. doi: 10.1038/nsmb.1891

Jones, P. M., O’Mara, M. L., and George, A. M. (2009). ABC transporters: a riddle wrapped in a mystery inside an enigma. Trends Biochem. Sci. 34, 520-531. doi: 10.1016/j.tibs.2009.06.004

Ketchem, R., Roux, B., and Cross, T. (1997). High-resolution polypeptide structure in a lamellar phase lipid environment from solid state NMR derived orientational constraints. Structure 5, 1655-1669. doi: 10.1016/S0969-2126(97)00312-2

Kühlbrandt, W. (2014). The resolution revolution. Science 343, 1443-1444. doi: $10.1126 /$ science. 1251652

Lange, A., Giller, K., Hornig, S., Martin-Eauclaire, M.-F., Pongs, O., Becker, S., et al. (2006). Toxin-induced conformational changes in a potassium channel revealed by solid-state NMR. Nature 440, 959-962. doi: 10.1038/nature04649

Lange, V., Becker-Baldus, J., Kunert, B., van Rossum, B.-J., Casagrande, F., Engel, A., et al. (2010). A MAS NMR study of the bacterial ABC transporter ArtMP. Chembiochem 11, 547-555. doi: 10.1002/cbic.200900472

Lehner, I., Basting, D., Meyer, B., Haase, W., Manolikas, T., Kaiser, C., et al. (2008). The key residue for substrate transport (Glu14) in the EmrE dimer is asymmetric. J. Biol. Chem. 283, 3281-3288. doi: 10.1074/jbc.M707899200

Lesage, A., Gardiennet, C., Loquet, A., Verel, R., Pintacuda, G., Emsley, L., et al. (2008). Polarization transfer over the water-protein interface in solids. Angew. Chem. Int. Ed Engl. 47, 5851-5854. doi: 10.1002/anie.200801110 
Li, Y., Berthold, D. A., Gennis, R. B., and Rienstra, C. M. (2008). Chemical shift assignment of the transmembrane helices of DsbB, a $20-\mathrm{kDa}$ integral membrane enzyme, by 3D magic-angle spinning NMR spectroscopy. Protein Sci. 17, 199-204. doi: 10.1110/ps.073225008

Liao, M., Cao, E., Julius, D., and Cheng, Y. (2013). Structure of the TRPV1 ion channel determined by electron cryo-microscopy. Nature 504, 107-112. doi: 10.1038/nature12822

Linser, R., Dasari, M., Hiller, M., Higman, V., Fink, U., Lopez del Amo, J. M., et al. (2011). Proton-detected solid-state NMR spectroscopy of fibrillar and membrane proteins. Angew. Chem. Int. Ed Engl. 50, 4508-4512. doi: 10.1002/anie.201008244

Liu, C. E., Liu, P. Q., and Ames, G. F. (1997). Characterization of the adenosine triphosphatase activity of the periplasmic histidine permease, a traffic ATPase (ABC transporter). J. Biol. Chem. 272, 21883-21891. doi: $10.1074 /$ jbc. 272.35.21883

Loquet, A., Bousset, L., Gardiennet, C., Sourigues, Y., Wasmer, C., Habenstein, B., et al. (2009). Prion fibrils of Ure2p assembled under physiological conditions contain highly ordered, natively folded modules. J. Mol. Biol. 394, 108-118. doi: 10.1016/j.jmb.2009.09.016

Lorch, M., Faham, S., Kaiser, C., Weber, I., Mason, A. J., Bowie, J. U., et al. (2005). How to prepare membrane proteins for solid-state NMR: a case study on the alpha-helical integral membrane protein diacylglycerol kinase from $E$. coli. Chembiochem 6, 1693-1700. doi: 10.1002/cbic.200500054

Lorieau, J. L., Day, L. A., and McDermott, A. E. (2008). Conformational dynamics of an intact virus: order parameters for the coat protein of Pfl bacteriophage. PNAS 105, 10366-10371. doi: 10.1073/pnas.0800405105

Marassi, F., and Opella, S. (2000). A solid-state NMR index of helical membrane protein structure and topology. J. Magn. Reson. 144, 150-155. doi: 10.1006/jmre.2000.2035

Martinez, L., Arnaud, O., Henin, E., Tao, H., Chaptal, V., Doshi, R., et al. (2014). Understanding polyspecificity within the substrate-binding cavity of the human multidrug resistance P-glycoprotein. FEBS J. 281, 673-682. doi: 10.1111 /febs. 12613

Mason, A. J., Siarheyeva, A., Haase, W., Lorch, M., van Veen, H., and Glaubitz, C. (2004). Amino acid type selective isotope labelling of the multidrug ABC transporter LmrA for solid-state NMR studies. FEBS Lett. 568, 117-121. doi: 10.1016/j.febslet.2004.05.016

McDermott, A. (2009). Structure and dynamics of membrane proteins by magic angle spinning solid-state NMR. Annu. Rev. Biophys. 38, 385-403. doi: 10.1146/annurev.biophys.050708.133719

McDermott, A., Polenova, T., Böckmann, A., Zilm, K. W., Paulsen, E. K., Martin, R. W., et al. (2000). Partial NMR assignments for uniformly (13C, $15 \mathrm{~N})$-enriched BPTI in the solid state. J. Biomol. NMR 16, 209-219. doi: 10.1023/A:1008391625633

Mehmood, S., Domene, C., Forest, E., and Jault, J.-M. (2012). Dynamics of a bacterial multidrug $\mathrm{ABC}$ transporter in the inward- and outward-facing conformations. PNAS 109, 10832-10836. doi: 10.1073/pnas. 1204067109

Miroux, B., and Walker, J. E. (1996). Over-production of proteins in Escherichia coli: mutant hosts that allow synthesis of some membrane proteins and globular proteins at high levels. J. Mol. Biol. 260, 289-298. doi: 10.1006/jmbi. 1996.0399

Morcombe, C. R., Gaponenko, V., Byrd, R. A., and Zilm, K. W. (2005). 13C CPMAS spectroscopy of deuterated proteins: CP dynamics, line shapes, and T1Relaxation. J. Am. Chem. Soc. 127, 397-404. doi: 10.1021/ja045581x

Murray, D. T., Griffin, J., and Cross, T. A. (2014a). Detergent optimized membrane protein reconstitution in liposomes for solid state NMR. Biochemistry 53, 2454-2463. doi: 10.1021/bi500144h

Murray, D. T., Hung, I., and Cross, T. A. (2014b). Journal of magnetic resonance. J. Magn. Reson. 240, 34-44. doi: 10.1016/j.jmr.2013.12.014

Newstead, S., Fowler, P. W., Bilton, P., Carpenter, E. P., Sadler, P. J., Campopiano, D. J., et al. (2009). Insights into how nucleotide-binding domains power ABC transport. Structure 17, 1213-1222. doi: 10.1016/j.str.2009.07.009

Ong, Y. S., Lakatos, A., Becker-Baldus, J., Pos, K. M., and Glaubitz, C. (2013). Detecting substrates bound to the secondary multidrug efflux pump EmrE by DNP-enhanced solid-state NMR. J. Am. Chem. Soc. 135, 15754-15762. doi: $10.1021 / \mathrm{ja} 402605 \mathrm{~s}$

Opella, S. J., and Marassi, F. M. (2004). Structure determination of membrane proteins by NMR spectroscopy. Chem. Rev. 104, 3587-3606. doi: $10.1021 / \mathrm{cr} 0304121$
Opella, S. J., Marassi, F. M., Gesell, J. J., Valente, A. P., Kim, Y., Oblatt-Montal, M., et al. (1999). Structures of the M2 channel-lining segments from nicotinic acetylcholine and NMDA receptors by NMR spectroscopy. Nat. Struct. Biol. 6, 374-379. doi: 10.1038/7610

Orelle, C., Gubellini, F., Durand, A., Marco, S., Lévy, D., Gros, P., et al. (2008). Conformational change induced by ATP binding in the multidrug ATP-binding cassette transporter BmrA $\dagger$. Biochemistry 47, 2404-2412. doi: 10.1021/bi702303s

Park, S. H., Das, B. B., Casagrande, F., Tian, Y., Nothnagel, H. J., Chu, M., et al. (2012). Structure of the chemokine receptor CXCR1 in phospholipid bilayers. Nature 491, 779-783. doi: 10.1038/nature11580

Rigaud, J. L., Pitard, B., and Levy, D. (1995). Reconstitution of membrane proteins into liposomes: application to energy-transducing membrane proteins. Biochim. Biophys. Acta 1231, 223-246. doi: 10.1016/0005-2728(95) 00091-V

Scholz, I., Huber, M., Manolikas, T., Meier, B. H., and Ernst, M. (2008). MIRROR recoupling and its application to spin diffusion under fast magicangle spinning. Chem. Phys. Lett. 460, 278-283. doi: 10.1016/j.cplett.2008. 05.058

Schuetz, A., Wasmer, C., Habenstein, B., Verel, R., Greenwald, J., Riek, R., et al. (2010). Protocols for the sequential solid-state NMR spectroscopic assignment of a uniformly labeled $25 \mathrm{kDa}$ protein: HET-s(1-227). Chembiochem 11, 1543-1551. doi: 10.1002/cbic.201000124

Sharma, M., Yi, M., Dong, H., Qin, H., Peterson, E., Busath, D. D., et al. (2010). Insight into the mechanism of the influenza A proton channel from a structure in a lipid bilayer. Science 330, 509-512. doi: 10.1126/science. 1191750

Shi, L., Kawamura, I., Jung, K.-H., Brown, L. S., and Ladizhansky, V. (2011). Conformation of a seven-helical transmembrane photosensor in the lipid environment. Angew. Chem. Int. Ed. Engl. 50, 1302-1305. doi: 10.1002/anie.201004422

Shi, L., Lake, E. M. R., Ahmed, M. A. M., Brown, L. S., and Ladizhansky, V. (2009). Solid-state NMR study of proteorhodopsin in the lipid environment: secondary structure and dynamics. Biochim. Biophys. Acta 1788, 2563-2574. doi: 10.1016/j.bbamem.2009.09.011

Sinnige, T., Weingarth, M., Renault, M., Baker, L., Tommassen, J., and Baldus, M. (2014). Solid-state NMR studies of full-length BamA in lipid bilayers suggest limited overall POTRA mobility. J. Mol. Biol. 426, 2009-2021. doi: 10.1016/j.jmb.2014.02.007

Steinfels, E., Orelle, C., Dalmas, O., Penin, F., Miroux, B., Di Pietro, A., et al. (2002). Highly efficient over-production in E. coli of YvcC, a multidrug-like ATP-binding cassette transporter from Bacillus subtilis. Biochim. Biophys. Acta 1565, 1-5. doi: 10.1016/S0005-2736(02)00515-1

Stevens, T. J., Fogh, R. H., Boucher, W., Higman, V. A., Eisenmenger, F., Bardiaux, B., et al. (2011). A software framework for analysing solid-state MAS NMR data. J. Biomol. NMR 51, 437-447. doi: 10.1007/s10858-011-9569-2

Studier, F. W. (2005). Protein production by auto-induction in high density shaking cultures. Protein Expr. Purif. 41, 207-234. doi: 10.1016/j.pep.2005. 01.016

Su, Y., Waring, A. J., Ruchala, P., and Hong, M. (2010). Membrane-bound dynamic structure of an arginine-rich cell-penetrating peptide, the protein transduction domain of HIV TAT, from solid-state NMR. Biochemistry 49, 6009-6020. doi: 10.1021/bi100642n

Takegoshi, K., Nakamura, S., and Terao, T. (2001). dipolar-assisted rotational resonance in magic-angle spinning NMR. Chem. Phys. Lett. 344, 631-637. doi: 10.1016/S0009-2614(01)00791-6

Tycko, R. (2011). Solid-state NMR studies of amyloid fibril structure. Annu. Rev. Phys. Chem. 62, 279-299. doi: 10.1146/annurev-physchem-032210103539

van Gammeren, A. J., Buda, F., Hulsbergen, F. B., Kiihne, S., Hollander, J. G., Egorova-Zachernyuk, T. A., et al. (2005). Selective chemical shift assignment of B800 and B850 bacteriochlorophylls in uniformly [13C,15N]-labeled light-harvesting complexes by solid-state NMR spectroscopy at ultra-high magnetic field. JACS 127, 3213-3219. doi: 10.1021/ ja044215a

Van Melckebeke, H., Wasmer, C., Lange, A., Ab, E., Loquet, A., Böckmann, A., et al. (2010). Atomic-resolution three-dimensional structure of HET-s(218289) amyloid fibrils by solid-state NMR spectroscopy. J. Am. Chem. Soc. 132, 13765-13775. doi: 10.1021/ja104213j 
Wang, Y., and Jardetzky, O. (2002). Probability-based protein secondary structure identification using combined NMR chemical-shift data. Protein Sci. 11, 852-861. doi: 10.1110/ps.3180102

Ward, A. B., Reyes, C. L., Yu, J., Roth, C. B., and Chang, G. (2007). Flexibility in the ABC transporter MsbA: alternating access with a twist. PNAS 104, 19005-19010. doi: 10.1073/pnas.0709388104

Wasmer, C., Lange, A., Van Melckebeke, H., Siemer, A. B., Riek, R., and Meier, B. H. (2008). Amyloid fibrils of the HET-s(218-289) prion form a beta solenoid with a triangular hydrophobic core. Science 319, 1523-1526. doi: 10.1126/science. 1151839

Wasmer, C., Schütz, A., Loquet, A., Buhtz, C., Greenwald, J., Riek, R., et al. (2009). The molecular organization of the fungal prion HET-s in its amyloid form. J. Mol. Biol. 394, 119-127. doi: 10.1016/j.jmb.2009.09.015

Wüthrich, K. (2003). NMR studies of structure and function of biological Macromolecules (Nobel Lecture). Angew. Chem. Int. Ed. 42, 3340-3363. doi: 10.1002/anie. 200300595

Zhou, Z., White, K. A., Polissi, A., Georgopoulos, C., and Raetz, C. R. (1998). Function of Escherichia coli MsbA, an essential ABC family transporter, in lipid A and phospholipid biosynthesis. J. Biol. Chem. 273, 12466-12475. doi: $10.1074 /$ jbc.273.20.12466
Conflict of Interest Statement: The authors declare that the research was conducted in the absence of any commercial or financial relationships that could be construed as a potential conflict of interest.

Received: 10 April 2014; paper pending published: 27 April 2014; accepted: 26 May 2014; published online: 12 June 2014.

Citation: Kunert B, Gardiennet C, Lacabanne D, Calles-Garcia D, Falson P, Jault J-M, Meier BH, Penin F and Böckmann A (2014) Efficient and stable reconstitution of the ABC transporter BmrA for solid-state NMR studies. Front. Mol. Biosci. 1:5. doi: 10.3389/fmolb.2014.00005

This article was submitted to Structural Biology, a section of the journal Frontiers in Molecular Biosciences.

Copyright (C) 2014 Kunert, Gardiennet, Lacabanne, Calles-Garcia, Falson, Jault, Meier, Penin and Böckmann. This is an open-access article distributed under the terms of the Creative Commons Attribution License (CCBY). The use, distribution or reproduction in other forums is permitted, provided the original author(s) or licensor are credited and that the original publication in this journal is cited, in accordance with accepted academic practice. No use, distribution or reproduction is permitted which does not comply with these terms. 